\title{
Diffuse anterior retinoblastoma: current concepts
}

This article was published in the following Dove Press journal:

OncoTargets and Therapy

22 July 2015

Number of times this article has been viewed

\begin{abstract}
Diffuse anterior retinoblastoma is a rare variant of retinoblastoma seeding in the area of the vitreous base and anterior chamber. Patients with diffuse anterior retinoblastoma are older than those with the classical types, with the mean age being 6.1 years. The original cells of diffuse anterior retinoblastoma are supposed to be cone precursor. Patients most commonly present with pseudouveitis, pseudohypopyon, and increased intraocular pressure. The retina under fundus examination is likely to be normal, and the clinical features mimic the inflammation progress, which can often lead to misdiagnosis. The published diffuse anterior retinoblastoma cases were diagnosed after fine-needle aspiration biopsy running the potential risk of inducing metastasis. The most common treatment for diffuse anterior retinoblastoma is enucleation followed by systematic chemotherapy according to the patient's presentation and clinical course. This review summarizes the recent advances in etiology (including tumorigenesis and cell origin), pathology, diagnosis, differential diagnosis, and new treatment. The challenges of early diagnosis and prospects are also discussed.
\end{abstract}

Keywords: pathology, microenvironment, treatment, diagnosis

\section{Introduction}

Retinoblastoma is a common intraocular malignancy in infancy or childhood, presenting the typical clinical features leukocoria (white reflections in pupil) and strabismus, with an incidence rate of approximately one in 15,000-20,000 live births worldwide. ${ }^{1-6}$ Most sufferers are diagnosed at less than 5 years old, with a median age of 18 months. ${ }^{1,2,4}$ Two centuries ago, retinoblastoma was first reported by Haye et al who described it as a neuroectodermal tumor within retina., ${ }^{5,6}$ According to different criteria, retinoblastoma can be classified as sporadic or familial and as unilateral or bilateral, respectively.,8

Retinoblastoma was also the first disease demonstrating a genetic defect in cancer research, and $R B 1$ is the only gene in which mutations are known to cause heritable predisposition to retinoblastoma. ${ }^{3} R B 1$ gene is localized to chromosome $13 \mathrm{q} 1.4$ and has an autosomal dominant pattern of inheritance. ${ }^{9,10}$ In both heritable and sporadic cases, biallelic mutations of the $R B 1$ tumor-suppressor gene initiate tumor growth. , $11-14,15^{-15}$ Normally, $\mathrm{pRb}$ encoded by $R B 1$ gene plays important roles in preventing the progression of the cell cycle from G1 to S phase through inhibiting E2F transcription factors (E2Fs) which act as important transcription regulators in eukaryotes. ${ }^{12,13,16-18}$ The $\mathrm{pRb}$ function is modulated by phosphorylation which is mediated by cyclin-dependent kinase (CDK)-cyclin complexes. ${ }^{19-21}$ And retinoblastoma does not originate from intrinsically death-resistant cells as previously thought. When RB1-deficient retinoblasts undergo p53-mediated apoptosis and exit the cell cycle, subsequently, MDMX (Mdm2 p53 binding protein homolog) protein overexpresses following MDMX gene amplifies, which are strongly selected for during tumor progression as a mechanism to suppress the $\mathrm{p} 53$ response in $R B 1$-deficient retinal cells. ${ }^{22-25}$ 
Retinoblastoma originates from cone precursors and performs various growth patterns, including: endophytic, exophytic, mixed endophytic-exophytic, intraretinal, diffuse infiltrating, and spontaneous regression/arrest (retinocytoma/ retinoma). ${ }^{26-30}$ Among these, diffuse infiltrating retinoblastoma is a rare type which has seed involvement of the retina with free tumor cells entering the aqueous humor, infiltrating the vitreous, and diffusely implanting on the anterior segment. ${ }^{31-35}$ Diffuse anterior retinoblastoma is an anterior variant of diffuse infiltrating retinoblastoma which results in tumor cells in the aqueous humor disseminating from inferior peripheral intraretinal focus seeding in the area of ciliary body, vitreous base, and anterior chamber. ${ }^{36-43}$ Features such as invisible retinal mass and anterior segment lesion infiltration mimic inflammatory processes in the anterior segment, which often leads to misdiagnosis of uveitis and endophthalmitis unless anterior chamber paracentesis or tissue sampling is performed. ${ }^{44,45}$ Therefore, the average onset age of diffuse anterior retinoblastoma is higher than that of the classical types. ${ }^{36}$

\section{Historical review}

Two centuries ago, Hayes first published a description of a neuroepiblastic tumor of the retina, which was later named as "retinoblastoma" in 1767. ${ }^{1-3}$ "Diffuse infiltrating retinoblastoma" was first suggested by Ashton in 1958 to describe the unusual nature of a flat neoplasm that seldom formed tumor masses in retina. ${ }^{31,32}$ Afterwards, Jijelava and Grossniklaus reported a case which was characterized by anterior chamber pseudohypopyon without visible retinal mess and finally named as "diffuse anterior retinoblastoma" in 1998. ${ }^{36}$ It was once believed that diffuse anterior retinoblastoma was unilateral and non-heritable, until 2009, when Crosby et al presented a case exhibiting a germline mutation of $R B 1$ that indicated that diffuse anterior retinoblastoma may in fact be heritable. ${ }^{37}$ Overall, a total of six cases have been reported; since then, little has been published on anterior diffuse retinoblastoma.

\section{Effect of microenvironment}

Microenvironment is considered to exert significant effects on the tumor progression for classical retinoblastoma. ${ }^{46}$ For example, under hypoxic conditions, active HIF-1 heterodimeric complex binds to core DNA sequences at the hypoxia response element, and thus activates multiple target genes including VEGF. ${ }^{46,47}$ Therefore, coordinate upregulation of HIF-1 and VEGF is involved in tumor angiogenesis, which induces neovascularization from the preexisting vessels, increasing the supply of nutrients to promote the proliferation and survival of tumor cells in a hostile microenvironment. ${ }^{47}$ To investigate the microenvironmental factor of tumorigenesis involved in diffuse anterior retinoblastoma, Crosby et al performed immunofluorescent stainings both on the intraretinal tumor and on tumor cells in the aqueous humor. ${ }^{37}$ Both types of sample were positive for vascular endothelial growth factor (VEGF) and negative for inducible nitric oxide synthase (iNOS) and hypoxia-inducible factor 1 (HIF-1); however, transforming growth factor $\beta$ (TGF- $\beta$ ) was positive in the aqueous humor tumor cells only. The results indicate that VEGF expressed by the intraretinal tumor did not appear to be mediated by HIF-1 or iNOS, which are the common pathways of ischemia mediating angiogenesis. ${ }^{37}$ The TGF- $\beta$ superfamily possesses three major functions in growth regulation and development: inhibit proliferation (of most cells, but can stimulate the growth of some mesenchymal cells), exert immunosuppressive effects, and enhance the formation of extracellular matrix. ${ }^{48,49}$ Among the functions, inhibition of growth by TGF- $\beta$ stems from a blockage of the cell cycle in the late G1 phase participates in $\mathrm{G} 1$ arrest with retinoblastoma proteins and members of the cyclin/CDK CDKI families. ${ }^{50,51}$ TGF- $\beta$ also inhibits cell proliferation through inducing the synthesis of 4EBP1 and CDKIs (p15, p21, and p57). ${ }^{52}$ The combination of 4EBP1 and eIF4E (eukaryotic initiation factor 4E) suppresses the protein translation, and CDKIs inhibit cell cycle progression through inhibiting activity of the cyclinCDK complex which is essential for G1/S transformation, contribute to phosphorylation of retinoblastoma proteins, and thus lead to tumor formation. ${ }^{51,52}$ Additionally, TGF- $\beta$ also inhibits expression of Cdc25a phosphatase, which is necessary for cyclin-CDK complex activation and negative regulation of factors including Id protein, E2F, and c-Myc driving the cell cycle progression and cell proliferation. ${ }^{49-51}$ Crosby et al speculated tumor seeds in aqueous humor acquire TGF- $\beta$ as a survival factor to aid in tumor formation and migration. ${ }^{37}$

\section{Pathology}

Under microscope, the tumor cells infiltrated diffusely throughout the anterior chamber, anterior vitreous, and posterior cornea are always in the forms of singles, clumps, or islands, which are similar to those seen in the earlier fine-needle aspiration biopsy (FNAB). They have small round basophilic shapes; high nuclear-to-cytoplasmic ratios; hyperchromatic nuclei; and presence of nuclear pyknosis and karyorrhexis, which suggests the existence of necrosis.

Pathologically, retinoblastoma consists of cells with round, oval, or spindle-shaped nuclei that are approximately 
twice the size of lymphocytes forming the structure of rosettes. The rosettes include Homer Wright and FlexnerWintersteiner (FW) rosettes, dependent on the stages of retinal differentiation, and these two rosettes are exclusively found in retinoblastoma. ${ }^{53}$ The lumen corresponds to subretinal space and stains with alcian blue (HR-AMP) that contains cytoplasmic extensions from the tumor cells. The cells surrounding the lumen are joined near the apices by intracellular connections (zonulae adherent), which are analogous to the external limiting membrane of retina. FW rosettes are not pathognomonic because they also occur in malignant medulloepitheliomas and some pineal tumors. ${ }^{53,54}$ Taking into account all reported cases, Homer Wright rosettes were present in two cases whereas FW rosettes were present in two other cases. ${ }^{37,38,41,42}$

On electron microscopy, tumor cells have a high nuclearto-cytoplasmic ratio, rare nucleoli, glycogen granules, intercellular junctions, sparse intracytoplasmic filaments, chromatin clumping, and cilia in the $9+0$ configuration (cilia-like structures with a ring of nine doublet microtubular structures but no central component) that is characteristic of retinoblastoma and retinal photoreceptors.

At present, there is not a standard consensus regarding immunohistochemical staining for retinoblastoma diagnosis, and the protocols performed in each case varied. However, several biomarkers were commonly used and manifested similar results. Neuron-specific enolase ([NSE] a glycolytic enzyme essentially confined to neurons) is observed positive in neuron processing of all layers in normal retina. ${ }^{55,56} \mathrm{NSE}$ was positive in two cases, ${ }^{38,39}$ which indicates that diffuse anterior retinoblastoma was of neuronal origin. Synaptophysin (a neuron-associated integral membrane glycoprotein of presynaptic vesicle) is concentrated in synaptic connections, while, in retinoblastomas, they exist in rosette-forming cells and in both plexiform layers. ${ }^{54,55}$ Synaptophysin was positive in two cases indicating a photoreceptor-like differentiation of this tumor. Vimentin, which immunolabels cells that undergo epithelialto-mesenchymal transition, was positive in Grossniklaus et $\mathrm{al}^{38}$ indicating acquisition of infiltration and metastasis ability in diffuse anterior retinoblastoma. Negativity in remainder biomarkers such as S-100 and glial fibrillary acidic protein (GFAP) also possesses significance. In normal retina, S-100 protein and GFAP are positive in astrocytes and Muller cells, while the reaction of these proteins are devoid in retinoblastoma tumor cells, which supports the view that retinoblastomas are composed of neuron-committed cells. S-100 was negative in three cases, and GFAP was negative in two cases. Moreover, mouse monoclonal anti-cytokeratin (MAK-6), AE1/AE3, leukocyte common antigen, and cluster of differentiation molecule 34 (CD34) each stained negatively in one case report.

\section{Diagnosis and differential diagnosis}

Diffuse anterior retinoblastoma is usually unilateral, and the average age of the disease is approximately 6.4 years. ${ }^{36}$ It was once believed that diffuse anterior retinoblastoma was sporadic, until 2009, when Crosby et al reported a germline mutation which had been previously reported in heritable retinoblastoma. ${ }^{37}$ In most cases, children present with pseudouveitis or pseudohypopyon, which mimic the inflammation process that often leads to misdiagnosis. Overall, a total of six cases have been reported; the clinical descriptions and pathological examinations are summarized in Table 1.

Redness, visual blurring, and iris depigmentation are often the chief complaints of the initial visits, and primary diagnosis can mistakenly lead to conjunctivitis, so children with the above symptoms should receive comprehensive examinations without only antibacterial eyedrops. Keratic precipitates and white fluffy exudates, which are common clinical features of granulomatous uveitis or Toxocara endophthalmitis, could also be noticed in such patients under slit-lamp examination. ${ }^{36-40}$ Gonioscopy can reveal a partly closed anterior chamber angle attributing to the obstruction of the trabecular meshwork from cellular debris. ${ }^{44}$ Commonly, intraocular pressure (IOP) of the patients is elevated, and the average IOP is about $35 \mathrm{mmHg}$, which can be explained by neovascularization of the iris and/or infiltration of tumor cells into Schlemm's canal or the trabecular meshwork. ${ }^{44}$ Some glaucomatous atrophy could also be noticed in corneal epithelium, optic nerve, and retina. Ectropion uveae can be occasionally identified, which results from fibrovascular tissue on the anterior surfaces of the iris leaflets. ${ }^{42}$ Fundus exam is likely to be normal, but one case identified a small peripheral retinal mass at the initial optical examination. ${ }^{37} \mathrm{~B}$-scan echography is always unable to detect a retinal mass or calcification. ${ }^{38}$

Differential diagnosis of diffuse anterior retinoblastoma is broad, including medulloepithelioma, sarcoidosis, idiopathic uveitis, metastatic neuroblastic tumor, fungal endophthalmitis, pars planitis, Toxocara endophthalmitis, leukemia, lymphoma, juvenile rheumatoid arthritis-associated uveitis, and retinoblastoma. ${ }^{56,57}$ Among these diseases, medulloepithelioma is the most significant one to be distinguished.

Medulloepitheliomas are typically malignant nonhereditary embryogenic neoplasms of the medullary epithelium almost always occurring in the ciliary body. ${ }^{58}$ Secondary glaucoma from iris neovascularization actually occurs more frequently with medulloepithelioma, occurring in $60 \%$ of 


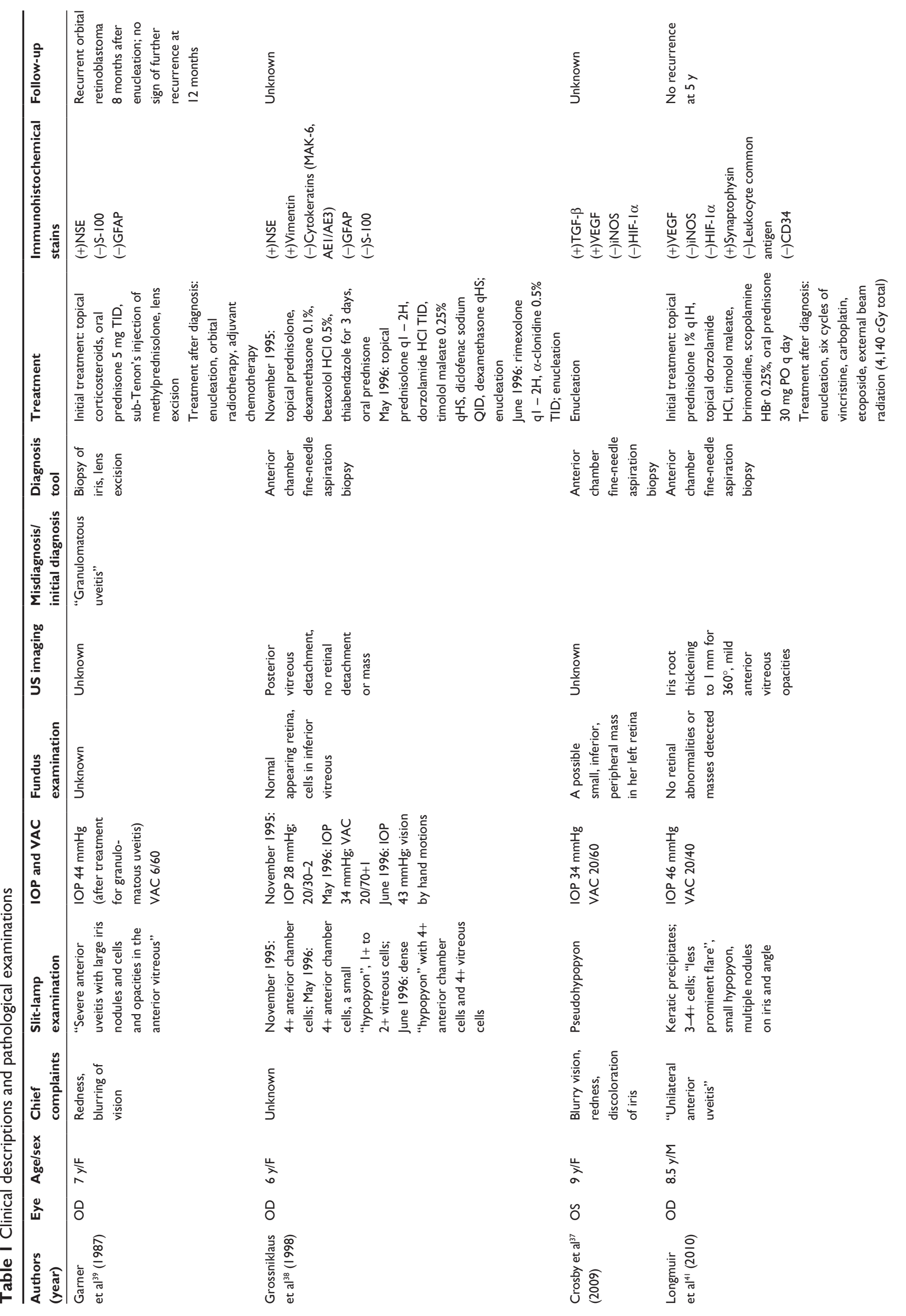




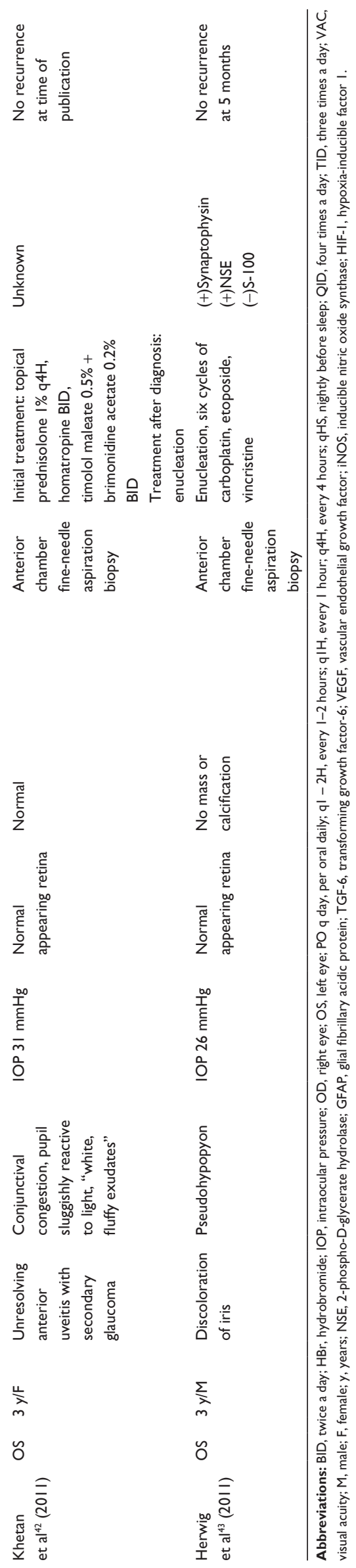

cases. ${ }^{59}$ Though nonteratoid medulloepitheliomas have been suggested to express NSE and synaptophysin, suggesting that they may be of neuronal origin, they also perform positive in biomarkers of GFAP, S-100, and vimentin, indicating that nonteratoid medulloepitheliomas may be multi-potential tumors, different from retinoblastoma composed of neurocommitted cells. Diffuse anterior retinoblastoma and medulloepithelioma are nearly indistinguishable on imaging, because both neoplasms are hyperintense to the vitreous on T1-weighted images and hypointense on T2-weighted images and enhance either uniformly or heterogeneously. ${ }^{60,61}$

Making a correct diagnosis still remains the greatest challenge in the management of the disease. Since this variant of retinoblastoma is extremely rare, the absence of an obvious retinal mass easily leads to misdiagnosis. In addition, since the diagnosis of diffuse anterior retinoblastoma relies upon an FNAB, which possesses the potential danger of aggressive tumor spreading, pursuing particular clinical hint presentation and seeking a diagnostic tool which could confirm the diagnosis without amplifying the tumor dissemination are of crucial importance.

\section{Management}

Attribute to the previous misdiagnosis, the majority of patients in the cases received topical corticosteroids to antiinflammation and medications lowering the IOP due to the increased IOP, which were not beneficial to diffuse anterior retinoblastoma. ${ }^{37,38,41,42}$ Accordingly, all the published cases performed enucleation followed by systematic chemotherapy.

The reported diffuse anterior retinoblastoma cases were unilateral and possessed anterior segment invasion, which are the absolute criteria for enucleation because these eyes have very limited visual potential in a prolonged period. The tumoral avascular features of this variant, which involves the anterior chamber and basal vitreous, are either poorly controlled by conventional therapies or beyond any conservative treatment, while traditional solid vascularized retinal tumors are easily accessible to various treatment modalities. ${ }^{62,63}$ In addition, these aggregations of tumor cells are virtually inaccessible to focal treatments and are highly radio resistant due to their hypoxic nature. ${ }^{64}$ So diffuse tumor cell control cannot be accomplished with any of the available modalities without enucleation, and the risk of keeping a blind eye cannot be justified when there is a risk for tumor spread and metastasis. Vital elements of enucleation include minimizing globe trauma and obtaining a long section of optic nerve in order to avoid seeds in it.

Following enucleation, histopathology should be examined to evaluate hints or presence of metastatic. High-risk cases include those with tumor invasion posterior to the 
lamina cribrosa of the optic nerve, those with $3 \mathrm{~mm}$ or greater of choroidal invasion, and those with a combination of any degree of optic nerve and uveal invasion, ${ }^{65}$ and additional systematic chemotherapy and consolidation are required to control the diffuse infiltrating seedings. ${ }^{66}$ Although intravenous chemotherapy protocols vary slightly between institutions, many centers are currently treating intraocular retinoblastoma with carboplatin, vincristine, and etoposide as a three-drug regimen given in two to six cycles. ${ }^{67}$

But to probe into the chemotherapy regimens and determine the standard chemotherapy, we still need more long-term clinical trials to investigate the therapeutic effect of treatment options that are individual or as a combination such as intravenous chemotherapy, intra-arterial chemotherapy, and intravitreal chemotherapy and thus to make further adjustment of management including selecting the appropriate adjuvant chemotherapy methods and deciding the number of the chemotherapy cycles, which is beneficial for the survival rate and living quality of the patients. Therefore, modern centers are treating retinoblastoma with a variety of modalities and individualizing the therapy according to the patient's presentation and clinical course.

No recurrences of tumor were reported in any of the published cases, though the accurate survival rate is difficult to extract because of the lack of long-term follow-ups.

\section{Conclusion}

Diffuse anterior retinoblastoma is a rare variant of diffuse infiltrating retinoblastoma that occurs unilaterally in children between the ages of 3 and 9 years. The majority of cases are nonhereditary; however, there is one reported case in a child with a germline mutation of the $R B 1$ gene. FNAB should only be performed at highly specialized centers with experienced ophthalmologists and ophthalmic pathologists as a last resort to narrow the differential diagnosis due to the risk of tumor dissemination. Simultaneously, exploring the particular clinical hint presentation and seeking diagnostic tools other than FNAB that could confirm the diagnosis without amplifying the tumor dissemination are of importance. Additionally, making adjustment of management such as selecting the appropriate adjuvant therapy methods is crucial for the survival rate and living quality of the patients. Detailed, long-term case reports following diagnosed children are still lacking.

\section{Acknowledgments}

This study was supported by the National Natural Science Foundation of China (number 81371017) and the Key Project of Science Research of Henan Province Education Committee (number 13A320427).

\section{Disclosure}

The authors report no conflicts of interest in this work.

\section{References}

1. Mehta M, Sethi S, Pushker N, et al. Retinoblastoma. Singapore Med J. 2012;53(2):128-135.

2. Aerts I, Lumbroso-Le Rouic L, Gauthier-Villars M, Brisse H, Doz F, Desjardins L. Retinoblastoma. Orphanet J Rare Dis. 2006;1:31.

3. Lohmann DR, Gallie BL. Retinoblastoma. In: Pagon RA, Adam MP, Ardinger HH, et al, editors. GeneReviews ${ }^{\mathbb{R}}$ [Internet]. Seattle: University of Washington, Seattle; 1993-2015. 2000 Jul 18 [updated 2013 Mar 28].

4. Shields CL, Shields JA. Diagnosis and management of retinoblastoma. Cancer Control. 2004;11(5):317-327.

5. Dimaras H, Kimani K, Dimba EA, et al. Retinoblastoma. Lancet. 2012; 379:1436-1446.

6. Victor M, Ditte J, Andrea W, Aaron S, Timothy G. Retinoblastoma. Curr Opin Ophthalmol. 2013;24:581-588.

7. Shields CL, Mashayekhi A, Au AK, et al. The International Classification of Retinoblastoma predicts chemoreduction success. Ophthalmology. 2006;113(12):2276-2280.

8. Rodriguez-Galindo C, Orbach DB, VanderVeen D. Retinoblastoma. Pediatr Clin North Am. 2015;62(1):201-223.

9. Thériault BL, Dimaras H, Gallie BL, Corson TW. The genomic landscape of retinoblastoma: a review. Clin Experiment Ophthalmol. 2014;42(1):33-52.

10. Mirakholi M, Mahmoudi T, Heidari M. MicroRNAs horizon in retinoblastoma. Acta Med Iran. 2013;51(12):823-829.

11. Chinnam M, Goodrich DW. RB1, development, and cancer. Curr Top Dev Biol. 2011;94:129-169.

12. Lai H, Ma F, Lai S. Identification of the novel role of $\mathrm{pRB}$ in eye cancer. J Cell Biochem. 2003;88(1):121-127.

13. Dannenberg JH, te Riele HP. The retinoblastoma gene family in cell cycle regulation and suppression of tumorigenesis. Results Probl Cell Differ. 2006;42:183-225.

14. Stahl A, Levy N, Wadzynska T, Sussan JM, Jourdan-Fonta D, Saracco JB. The genetics of retinoblastoma. Ann Genet. 1994;37(4):172-178.

15. DiCiommo D, Gallie BL, Bremner R. Retinoblastoma: the disease, gene and protein provide critical leads to understand cancer. Semin Cancer Biol. 2000;10(4):255-269.

16. Giacinti C, Giordano A. RB and cell cycle progression. Oncogene. 2006;25(38):5220-5227.

17. Goodrich DW. The retinoblastoma tumor-suppressor gene, the exception that proves the rule. Oncogene. 2006;25(38):5233-5243.

18. Sun A, Bagella L, Tutton S, Romano G, Giordano A. From G0 to S phase: a view of the roles played by the retinoblastoma $(\mathrm{Rb})$ family members in the Rb-E2F pathway. J Cell Biochem. 2007;102(6):1400-1404.

19. Sidle A, Palaty C, Dirks P, et al. Activity of the retinoblastoma family proteins, pRB, p107, and p130, during cellular proliferation and differentiation. Crit Rev Biochem Mol Biol. 1996;31(3):237-271.

20. Indovina P, Marcelli E, Casini N, Rizzo V, Giordano A. Emerging roles of RB family: new defense mechanisms against tumor progression. J Cell Physiol. 2013;228(3):525-535.

21. Laurie NA, Donovan SL, Shih CS, et al. Inactivation of the p53 pathway in retinoblastoma. Nature. 2006;444(7115):61-66.

22. Zielinski B, Gratias S, Toedt G, et al. Detection of chromosomal imbalances in retinoblastoma by matrix-based comparative genomic hybridization. Genes Chromosomes Cancer. 2005;43(3):294-301.

23. Mairal A, Pinglier E, Gilbert E, et al. Detection of chromosome imbalances in retinoblastoma by parallel karyotype and CGH analyses. Genes Chromosomes Cancer. 2000;28(4):370-379.

24. Chen D, Pajovic S, Duckett A, Brown VD, Squire JA, Gallie BL. Genomic amplification in retinoblastoma narrowed to 0.6 megabase on chromosome $6 \mathrm{p}$ containing a kinesin-like gene, RBKIN. Cancer Res. 2002;62(4):967-971.

25. Di Fiore R, D'Anneo A, Tesoriere G, Vento R. RB1 in cancer: different mechanisms of RB1 inactivation and alterations of $\mathrm{pRb}$ pathway in tumorigenesis. J Cell Physiol. 2013;228(8):1676-1687. 
26. Xu XL, Singh HP, Wang L, et al. Rb suppresses human cone-precursorderived retinoblastoma tumours. Nature. 2014;514:385-388.

27. Munier FL. Classification and management of seeds in retinoblastoma. Ellsworth Lecture Ghent August 24th 2013. Ophthalmic Genet. 2014;35(4):193-207.

28. Houston SK, Murray TG, Wolfe SQ, Fernandes CE. Current update on retinoblastoma. Int Ophthalmol Clin. 2011;51(1):77-91.

29. Kiss S, Leiderman YI, Mukai S. Diagnosis, classification, and treatment of retinoblastoma. Int Ophthalmol Clin. 2008;48(2):135-147.

30. Bremner R, Sage J. Cancer: the origin of human retinoblastoma. Nature. 2014;514(7522):312-313.

31. Morgan G. Diffuse infiltrating retinoblastoma. Br J Ophthalmol. 1971; 55:600-606

32. Schofield PB. Diffuse infiltrating retinoblastoma. Br J Ophthalmol. 1960;44:35-41.

33. Shields CL, Ghassemi F, Tuncer S, Thangappan A, Shields JA. Clinical spectrum of diffuse infiltrating retinoblastoma in 34 consecutive eyes. Ophthalmology. 2008;115(12):2253-2258.

34. Bhatnagar R, Vine AK. Diffuse infiltrating retinoblastoma. Ophthalmology. 1991;98(11):1657-1661.

35. Brisse HJ, Lumbroso L, Fréneaux PC, et al. Sonographic, CT, and MR imaging findings in diffuse infiltrative retinoblastoma: report of two cases with histologic comparison. AJNR Am J Neuroradiol. 2001; 22(3):499-504.

36. Jijelava KP, Grossniklaus HE. Diffuse anterior retinoblastoma: a review. Saudi J Ophthalmol. 2013;27:135-139.

37. Crosby MB, Hubbard GB, Gallie BL, Grossniklaus HE. Anterior diffuse retinoblastoma: mutational analysis and immunofluorescence staining. Arch Pathol Lab Med. 2009;133(8):1215-1218.

38. Grossniklaus HE, Dhaliwal RS, Martin DF. Diffuse anterior retinoblastoma. Retina. 1998;18:238-241.

39. Garner A, Kanski JJ, Kinnear F. Retinoblastoma: report of a case with minimal retinal involvement but massive anterior segment spread Br J Ophthalmol. 1987;71(11):858-863.

40. Whitcup SM, Park WS, Gasch AT, et al. Use of microdissection and molecular genetics in the pathologic diagnosis of retinoblastoma. Retina. 1999;19(4):318-324.

41. Longmuir SQ, Syed NA, Boldt HC. Diffuse anterior retinoblastoma without retinal involvement. Ophthalmology. 2010;117(10):2034-2038

42. Khetan V, Sudrik S, Singh S, Gopal L, Krishnakumar S. Diffuse anterior retinoblastoma with undetectable retinal involvement. J Pediatr Ophthalmol Strabismus. 2011;48 Online:e7-e9.

43. Herwig MC, Hubbard GB, Wells JR, Grossniklaus HE. [Diffuse anterior retinoblastoma]. Ophthalmologe. 2011;108(10):969-972. German.

44. Saket RR, Mafee MF. Anterior-segment retinoblastoma mimicking pseudoinflammatory angle-closure glaucoma: review of the literature and the important role of imaging. AJNR Am J Neuroradiol. 2009;30(8):1607-1609.

45. Balmer A, Zografos L, Munier F. Diagnosis and current management of retinoblastoma. Oncogene. 2006;25(38):5341-5349.

46. Ji RC. Hypoxia and lymphangiogenesis in tumor microenvironment and metastasis. Cancer Lett. 2014;346(1):6-16.

47. Gao Y, Jing M, Ge R, Zhou Z, Sun Y. Inhibition of hypoxia inducible factor $1 \alpha$ by siRNA-induced apoptosis in human retinoblastoma cells. J Biochem Mol Toxicol. 2014;28(9):394-399.

48. Massagué J, Cheifetz S, Laiho M, Ralph DA, Weis FM, Zentella A. Transforming growth factor-beta. Cancer Surv. 1992;12:81-103.

OncoTargets and Therapy

\section{Publish your work in this journal}

OncoTargets and Therapy is an international, peer-reviewed, open access journal focusing on the pathological basis of all cancers, potential targets for therapy and treatment protocols employed to improve the management of cancer patients. The journal also focuses on the impact of management programs and new therapeutic agents and protocols on
49. Horowitz JM. Regulation of transcription by the retinoblastoma protein. Genes Chromosomes Cancer. 1993;6(2):124-131.

50. Lawrence DA. Transforming growth factor-beta: a general review. Eur Cytokine Netw. 1996;7(3):363-374.

51. Ravitz MJ, Wenner CE. Cyclin-dependent kinase regulation during G1 phase and cell cycle regulation by TGF-beta. Adv Cancer Res. 1997;71: 165-207.

52. Chiarugi V, Magnelli L, Cinelli M. Complex interplay among apoptosis factors: RB, p53, E2F, TGF-beta, cell cycle inhibitors and the bcl2 gene family. Pharmacol Res. 1997;35(4):257-261.

53. Das D, Bhattacharjee K, Barthakur SS, et al. A new rosette in retinoblastoma. Indian J Ophthalmol. 2014;62(5):638-641.

54. Ts'o MO, Zimmerman LE, Fine BS. The nature of retinoblastoma. I. Photoreceptor differentiation: a clinical and histopathologic study. Am J Ophthalmol. 1970;69(3):339-349.

55. Yuge K, Nakajima M, Uemura Y, Miki H, Uyama M, Tsubura A. Immunohistochemical features of the human retina and retinoblastoma. Virchows Arch. 1995;426(6):571-575.

56. Dyer MA, Bremner R. The search for the retinoblastoma cell of origin. Nat Rev Cancer. 2005;5(2):91-101.

57. Temming P, Lohmann D, Bornfeld N, Sauerwein W, Goericke SL, Eggert A. Current concepts for diagnosis and treatment of retinoblastoma in Germany: aiming for safe tumor control and vision preservation. Klin Padiatr. 2012;224(6):339-347.

58. Kim JW, Abramson DH, Dunkel IJ. Current management strategies for intraocular retinoblastoma. Drugs. 2007;67(15):2173-2185.

59. McLean IW. Retinoblastomas, retinocytomas, and pseudoretinoblastomas. In: Spencer WH, editor. Ophthalmic Pathology: An Atlas and Textbook. Vol 2. 4th ed. Philadelphia: Saunders; 1996:1345-1351.

60. Shields JA, Eagle RC Jr, Shields CL, Potter PD. Congenital neoplasms of the nonpigmented ciliary epithelium (medulloepithelioma). Ophthalmology. 1996;103(12):1998-2006.

61. Vajaranant TS, Mafee MF, Kapur R, Rapoport M, Edward DP. Medulloepithelioma of the ciliary body and optic nerve: clinicopathologic, CT, and MR imaging features. Neuroimaging Clin N Am. 2005; 15(1):69-83

62. Shields CL, Kaliki S, Rojanaporn D, Al-Dahmash S, Bianciotto CG, Shields JA. Intravenous and intra-arterial chemotherapy for retinoblastoma: what have we learned? Curr Opin Ophthalmol. 2012;23(3): 202-209.

63. Chintagumpala M, Chevez-Barrios P, Paysse EA, Plon SE, Hurwitz R. Retinoblastoma: review of current management. Oncologist. 2007;12(10): 1237-1246.

64. Shields CL, Lally SE, Leahey AM, et al. Targeted retinoblastoma management: when to use intravenous, intra-arterial, periocular, and intravitreal chemotherapy. Curr Opin Ophthalmol. 2014;25(5):374-385.

65. Shields CL, Shields JA. Retinoblastoma management: advances in enucleation, intravenous chemoreduction, and intra-arterial chemotherapy. Curr Opin Ophthalmol. 2010;21(3):203-212.

66. Bhavsar D, Subramanian K, Sethuraman S, Krishnan UM. Management of retinoblastoma: opportunities and challenges. Drug Deliv. Epub 2015 Mar 11.

67. Shields CL, Manjandavida FP, Lally SE, et al. Intra-arterial chemotherapy for retinoblastoma in 70 eyes: outcomes based on the international classification of retinoblastoma. Ophthalmology. 2014;121(7): $1453-1460$

\section{Dovepress}

patient perspectives such as quality of life, adherence and satisfaction. The manuscript management system is completely online and includes a very quick and fair peer-review system, which is all easy to use. Visit http://www.dovepress.com/testimonials.php to read real quotes from published authors. 